\title{
El comentario lingüístico de textos como mediador de las tareas de escritura
}

\author{
Inmaculada López \\ Universidad Autónoma de Barcelona, España
}

\section{Introducción}

Las clases de lengua y literatura castellanas de segundo de bachillerato del curso 20092010 iniciaban el nuevo recorrido LOE que implicaba la reducción de horas de tres a dos en este nivel. Con el fin de optimizar al máximo este tiempo lectivo, se diseñó un procedimiento de aprendizaje de la lengua y de la escritura basado en el comentario lingüístico de textos. Con él se pretendía trabajar de manera integrada la competencia metalingüística y la competencia escrita. El principal problema que manifestaban los estudiantes era cómo afrontar este tipo de textos académicos, cómo redactarlo, puesto que era la primera vez que lo ponían en práctica; se había de prever una estrategia que les preparara para la redacción del comentario lingüístico y que también les facilitara su consciencia como escritores y los mecanismos que podían utilizar para ello. Se aplicó al comentario lingüístico una metodología de escritura basada en el trabajo cooperativo y en la reflexión sobre el texto.

Se plantean aquí, pues, dos vertientes de un mismo problema: por una parte, las dificultades de expresión escrita del alumnado, al que le cuesta concienciarse de la situación comunicativa pertinente en este caso, sobre todo si tenemos en cuenta que se enfrenta a un nuevo género cuya intención y estructura desconocen, y el proceso de escritura con que debe hacerle frente; por otra, un nuevo modo de aprender lengua, de hablar de la lengua, a partir del comentario lingüístico de textos, en una situación de aprendizaje diferente para ellos.

El objetivo de este trabajo no era analizar las teorías lingüísticas subyacentes en el comentario lingüístico, ni siquiera la estrategia de enseñanza y aprendizaje que se utilizaba en la asignatura de Lengua castellana en bachillerato, sino inquirir la influencia de esta metodología sobre la mejora de la competencia escrita del alumnado, ver cómo 
lo ayuda a adquirir estrategias que pueda desarrollar para mejorar la composición escrita y autorregularse.

\section{Marco de referencia}

La base teórica sobre la que se presenta este trabajo tiene dos ejes. Por una parte, los fundamentos que vienen a ser su punto de partida y que se resumen en el concepto de género discursivo y cómo se relaciona con el contexto en que se desarrolla; la propia reflexión sobre la lengua que se realiza a lo largo de toda la secuencia de enseñanzaaprendizaje; finalmente, el proceso de composición escrita, su complejidad y las necesarias ayudas que es preciso poner a disposición del alumnado para su desenvolvimiento. El núcleo de la investigación está centrado en una estrategia de enseñanza-aprendizaje que toma como referencia el desarrollo de una secuencia didáctica de composición escrita cuyo producto será el comentario lingüístico.

La estrategia es un proceso complejo en el que intervienen diversos elementos: La reflexión lingüística en sí misma que conduce al conocimiento de la lengua, la necesidad de leer, hablar y escribir sobre contenidos lingüísticos, que está estructurada bajo la mirada de la lingüística textual y, parcialmente, de una gramática pedagógica, en tanto se busca partir del texto real para acercarse al conocimiento de la lengua y la búsqueda de regularidades. Partimos de Camps (2005) y Camps y Zayas (2006).

El objetivo de aprendizaje que constituye eje central de la propuesta y que consiste en enfrentarse a la escritura de un género discursivo muy concreto y desconocido en principio por el alumnado. Este punto condiciona la estrategia de enseñanza y aprendizaje de la escritura para la que se ha de habilitar una serie de elementos de reflexión. Se tiene en consideración la noción de género de Bajtin (1982), quien afirma que se caracteriza por su contenido temático, por su estilo verbal (la selección de los recursos léxicos, fraseológicos y gramaticales), por su estructuración y, sobre todo, por la intención que los guía. De esta manera, se pueden establecer ciertas regularidades o formas genéricas estables de determinados textos pertenecientes a diversas esferas a partir de las características mencionadas.

Esta noción de género se complementa con la idea de texto empírico de Bronckart et al (1985), para quien el producto final que escriben los estudiantes -texto 
empírico- es el resultado: de la inmersión en el contexto que le da sentido, una situación de enseñanza-aprendizaje de la lengua castellana en bachillerato; del proceso de redacción de un género discursivo de carácter académico, el comentario lingüístico; de un objeto de estudio, el texto perteneciente a un ámbito de conocimiento determinado, que es a su vez la manifestación de una acción discursiva tipificada, de un género (humanístico, periodístico, científico), además de los aspectos lingüísticos que en él se producen. Podríamos representarlo en el siguiente esquema (cuadro 1):

Cuadro 1: Esquema de los géneros implicados en el proceso

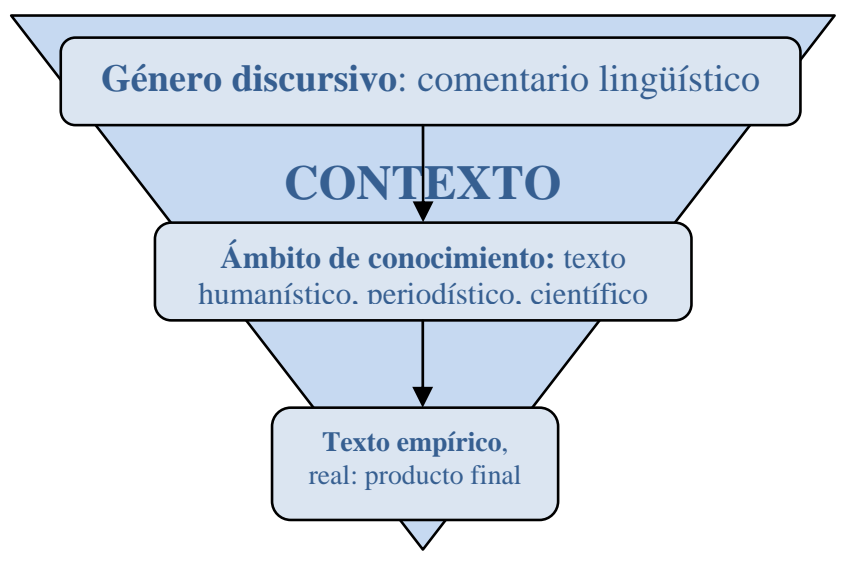

La necesidad de estructuración clara del proceso coincidente con los tres pasos de las secuencias didácticas para aprender a escribir (Camps 2003), que incluyen la redacción de un producto final síntesis de las actividades y reflexiones previas. En la preparación, fase dedicada a plantear el objetivo, a detectar la Zona de Desarrollo Próximo de que habla Vigotsky (1995), y a preparar los instrumentos necesarios para el trabajo, se explican los rasgos lingüísticos que se incorporan del nuevo ámbito y se incluye una actividad de modelaje a partir de un texto que les sirve de modelo sobre el cual se aportan los viejos conocimientos y los nuevos que se acaban de incorporar.

En la fase de desarrollo de una secuencia didáctica se dan una serie de actividades que irán permitiendo, por una parte, desarrollar los conocimientos lingüísticos que se requieran para el cumplimiento de la tarea; por otra, ahondar en la progresiva autorregulación del alumnado en la tarea. En esta fase del comentario lingüístico tienen lugar las diversas interacciones y enriquecimientos que los grupos de trabajo o de crítica aportan para la confección del comentario final. En la fase de 
evaluación de una secuencia didáctica, se redacta el informe o trabajo final, síntesis de todo el proceso de trabajo y objetivo último de la propia secuencia. En nuestro caso, se redacta el texto definitivo, intervienen los mismos grupos de trabajo, que se evalúan ellos mismos el resultado (autoevaluación), y la profesora, con su evaluación externa. Actúan en una doble vertiente las secuencias didácticas para aprender a escribir y para aprender gramática porque este género del comentario lingüístico requiere de ambas y las desarrolla en paralelo.

La capacidad de autonomía en el proceso y autorregulación del alumnado, a través de instrumentos como las pautas (Ribas 1997; Milian 2004), las cuales permiten la interacción oral y escrita en diversas manifestaciones y agrupaciones: formación de grupos de trabajo y de grupos de crítica; intercambio de versiones para el contraste de miradas, que pretenden la visión poliédrica de los textos; la guía enmascarada del docente en las mismas pautas (por cuanto las mismas pautas contenían la guía de los contenidos que debían desarrollar) y en la facilitación de los contenidos escritos de lengua como instrumentos de consulta y de estudio, que da protagonismo a la actuación del estudiante. Han sido guías inestimables en este punto los trabajos de Björk y Blomstrand (2006) y de Jorba y Casellas (1996).

En fin, una visión holística del estudio y expresión de la lengua que no atomiza, sino que integra. Que incita a leer, a hablar y a escribir en el presupuesto de que sólo integrando conocimientos y estrategia, el alumnado puede apropiarse de esos contenidos, puede llegar a entenderlos y a asimilarlos. Y que no se puede llegar a esa comprensión y asimilación de conocimientos y estrategia si no es compartiéndolos y contrastándolos con otros.

\section{Descripción de la estrategia o propuesta de enseñanza/aprendizaje}

La secuencia didáctica concreta realizada en el aula tiene como objetivo la escritura de un comentario lingüístico de un texto científico. Las actividades que se llevan a cabo están ordenadas de la siguiente manera:

La profesora comenta en clase, en interacción con los alumnos, un texto científico de carácter divulgativo con trazas de subjetividad. Se pretende que se tomen ideas, siguiendo el esquema del comentario lingüístico, pero abriendo puertas a la 
interpretación crítica del texto. Actuaría como un modelaje previo, en tanto se les ofrece un ejemplo del modelo de comentario que se les pide. Después se les da un texto científico-técnico, esta vez plenamente objetivo, para que todo el grupo clase realice sobre él un comentario lingüístico.

Los estudiantes disponen de un cuaderno teórico de lengua que sigue los pasos del comentario que se les ofrece de guía cuyo esquema de análisis textual se estructura tal como muestra el cuadro $2^{1}$.

Cuadro 2: Esquema de los contenidos del comentario lingüístico

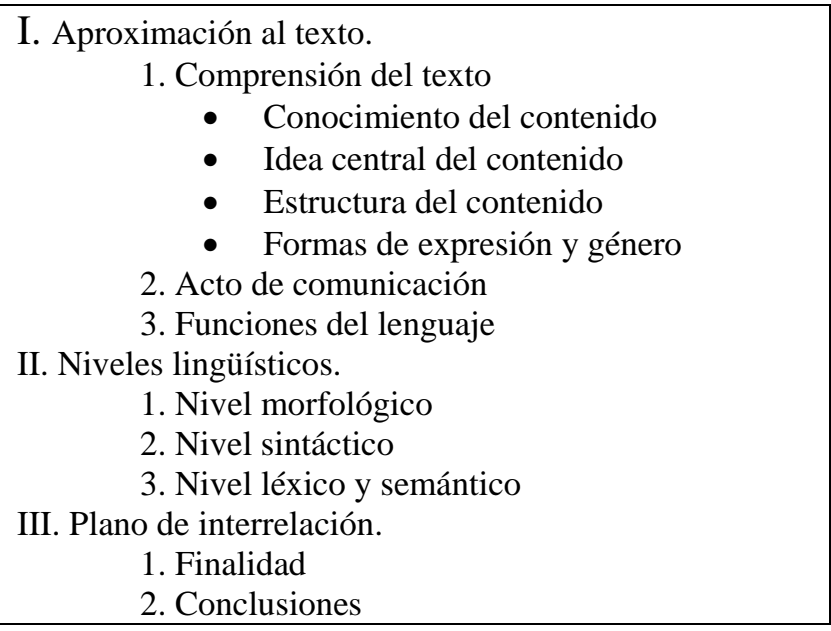

Como se puede ver, se parte de un primer estadio de aproximación al texto en el que se debe tener en cuenta de qué se habla, qué estructura tiene el texto, a qué género pertenece, cuál es su emisor, el receptor posible, el contexto en que surge y la intención que pretende. Se trata de una parte contextualizadora para emprender un análisis más detallado de la lengua.

En la segunda parte se acometen los niveles lingüísticos. A los estudiantes se les lleva paso a paso por las diferentes categorías gramaticales para que observen cuáles aparecen y por qué, en función de lo que han observado en la aproximación del texto. El nivel sintáctico no lo abordamos totalmente hasta el tercer trimestre, con lo cual este comentario, que se ubica en el segundo trimestre, no se fija apenas en el tipo de sintaxis que aparece en el texto estudiado. Sí se tiene en cuenta el nivel léxico y semántico. Finalmente el alumnado debe realizar una conclusión sintética que dé coherencia a la primera parte y a la segunda; es lo que se denomina, en el comentario lingüístico, plano de interrelación. 
Todo ello se debe desarrollar en forma de texto expositivo objetivo y en registro formal. Se pide a los estudiantes que eviten los títulos de los niveles y que en lugar de ellos utilicen marcadores de discurso que ordenen las distintas partes del trabajo. También deben aportar ejemplos de todos los elementos que van analizando para ilustrar o demostrar que es cierto lo que afirman que se produce en el texto comentado, e interpretar los diferentes elementos que encuentran a la luz del contexto en que se inscribe el texto, de forma que si hablan de la abundancia de nombres concretos, lo justifiquen por el tema o ámbito al que pertenece el texto, que en este caso, es el científico.

Para desarrollar la parte teórica disponen de tres materiales diferentes:

1. El comentario lingüístico teórico con la estructura global del comentario y todo el estudio de la lengua.

2. Una parte más específica de estudio de la lengua con esos mismos recursos seleccionados en función de las variables del texto que estaban tratando en clase en cada momento, en este caso, el texto científico. El alumnado tenía dificultades para concretar los elementos lingüísticos específicos que debían tener en cuenta en un texto determinado, por ejemplo el científico, si bien este documento en realidad es una concreción del primero mencionado en el punto anterior.

3. Un esquema-guión de la unidad relativa a los textos científicos que se explicó en clase y que orientaba al alumnado en la búsqueda de los elementos lingüísticos que podía esperar en su texto.

4. El alumnado debía tener en cuenta estos materiales, complementarios en sus contenidos, para realizar su comentario; se trata de tres fuentes de consulta diferentes.

5. Previa reflexión individual, los grupos de trabajo [GT], compuestos por tres personas, pactan un guión-resumen para el comentario lingüístico. En él llenan de contenidos el borrador que luego redactarán de manera individual. Se deben basar en el esquema mostrado anteriormente, pero atendiendo a las características específicas del texto que se les propone analizar.

6. Este primer borrador (B1) individual los estudiantes lo llevan al grupo de crítica [GC], formado por personas procedentes de tres grupos de trabajo diferentes. Cada una lee y comenta los borradores de los otros dos compañeros mediante una guía de 
crítica (pauta) que contiene aspectos de contenido y de forma del escrito. Al final han de rellenar las pautas para comentarlas después con los autores de los textos, calificar esos textos y justificar la nota. Esa misma pauta para el grupo de crítica les sirve a los autores de los textos a redactarlos, ya que tienen utilidad también como criterios de redacción y de evaluación al tiempo.

7. Cada autor modifica su borrador según las sugerencias del grupo de crítica (segundo borrador, B2) y lo lleva nuevamente al GT, del que saldrá el texto definitivo, que entregarán a la profesora (comentario lingüístico). Con el comentario lingüístico aportan también una hoja de autoevaluación colectiva.

El esquema de actuación se podría visualizar según se muestra en el cuadro 3:

Cuadro 3: Esquema de actuación

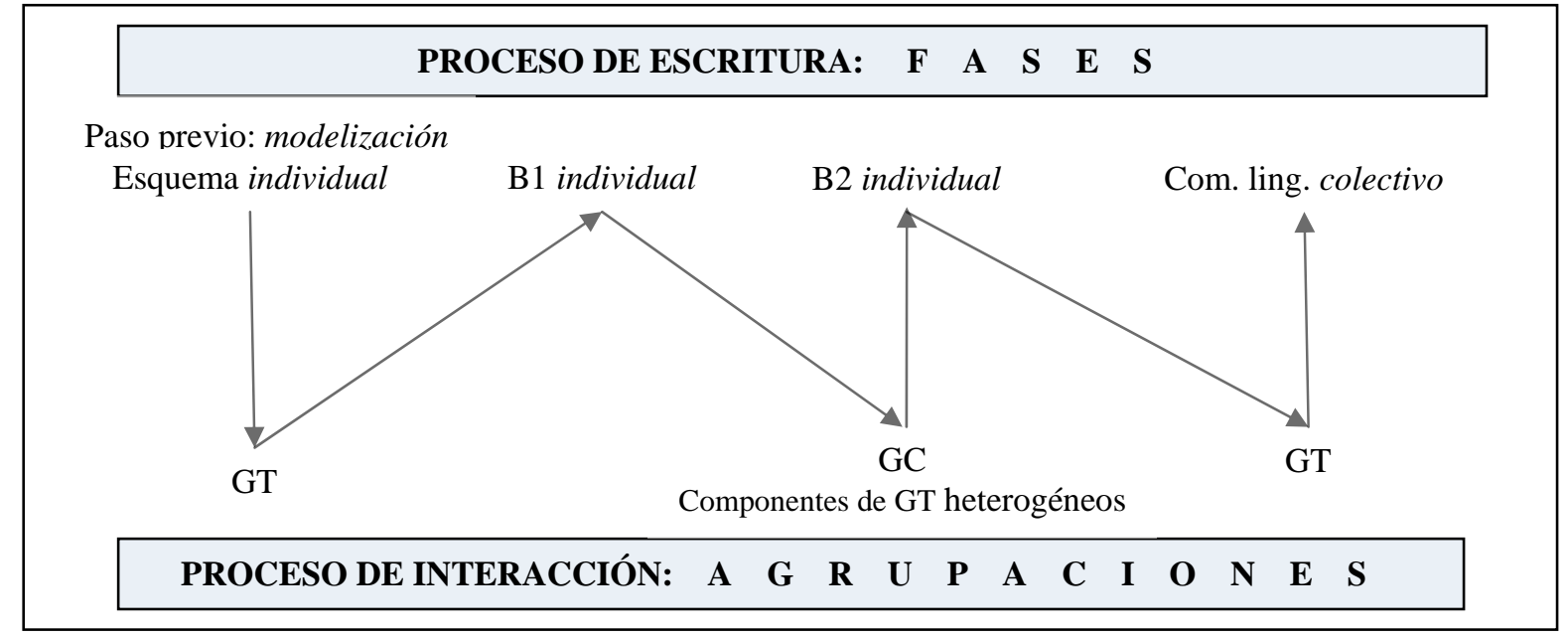

\section{Objetivos y preguntas de la investigación}

La pregunta central de investigación es la siguiente: ¿Escribir sobre la lengua aporta conocimientos sobre la manera de escribir sobre la lengua? Y las preguntas específicas:

- ¿QQué papel tiene la interacción entre alumnos en el proceso de apropiación de los conocimientos lingüísticos y del proceso de escritura?

- ¿Puede contribuir a esa apropiación la guía con pautas?

- ¿Pueden ayudar en el proceso de apropiación la evaluación mutua y la autoevaluación del alumnado según unos criterios preestablecidos? 
Partimos de la idea de que el conocimiento sobre la lengua, pero también la planificación de la escritura, pueden ayudar al alumnado a mejorar sus escritos académicos; igualmente, la interacción de los estudiantes entre ellos mismos y con la profesora, y la guía pautada de todo el proceso, tanto del estudio de la lengua como de la misma escritura.

Se determina, pues, como objetivo general detectar cómo este planteamiento específico de E/A ayuda a percibir la lengua como un todo integrado en que los conocimientos sobre la lengua y la reflexión lingüística colaboran en la competencia escrita del alumnado. No se puede mejorar la competencia escrita si no hay reflexión sobre la lengua.

No obstante, podemos decir que hay otra finalidad en la investigación: incidir en la práctica docente. Las conclusiones a las que se llegue deberían incitar mejoras en la estrategia y en los contenidos que se plantean.

\section{La metodología de la investigación}

El trabajo se fundamenta en una metodología cualitativa y etnográfica de investigaciónacción, ya que quien investiga es, a la vez, docente en el aula. Además, un objetivo que se propone este trabajo es comprobar que esta estrategia o metodología de trabajo en el aula es transferible a otras situaciones relacionadas con la materia y con el comentario lingüístico.

Los objetivos específicos que se definen y los datos que se han recogido son los recogidos en el cuadro 4.

Cuadro 4: Objetivos y datos de la investigación

\begin{tabular}{|l|l|}
\hline \multicolumn{1}{|c|}{ Objetivos específicos } & \multicolumn{1}{c|}{ Datos } \\
\hline $\begin{array}{l}\text { Describir la interacción escrita que se establece entre los primeros } \\
\text { borradores individuales y los diferentes grupos de crítica que los } \\
\text { valoran }\end{array}$ & $\begin{array}{l}\text { Pauta del grupo de crítica. Se } \\
\text { analizan los 22 estudiantes }\end{array}$ \\
\hline $\begin{array}{l}\text { Destacar las modificaciones que se han producido en el segundo } \\
\text { borrador, el que presentan al grupo de trabajo, con respecto del } \\
\text { primero, que era individual }\end{array}$ & $\begin{array}{l}\text { Segundo borrador. Se analizan } \\
\text { tres grupos de trabajo }\end{array}$ \\
\hline $\begin{array}{l}\text { Comprobar si hay cambios significativos en el comentario } \\
\text { lingüístico definitivo, a raíz de los comentarios recibidos por los } \\
\text { diferentes grupos de crítica que han actuado sobre los componentes } \\
\text { del grupo de trabajo }\end{array}$ & $\begin{array}{l}\text { Comentario lingüístico } \\
\text { definitivo. Se analizan tres } \\
\text { grupos de trabajo }\end{array}$ \\
\hline Comprobar si las pautas ofrecidas a los grupos de crítica son & Entrevista a tres estudiantes de \\
\hline
\end{tabular}




\begin{tabular}{|l|l|}
\hline cómodas de utilizar y útiles en función del objetivo & niveles y resultados diferentes \\
\hline $\begin{array}{l}\text { Detectar la valoración que los estudiantes hacen del proceso de } \\
\text { trabajo y del resultado final }\end{array}$ & $\begin{array}{l}\text { Pauta de autoevaluación del } \\
\text { grupo de trabajo. Se analizan los } \\
\text { 22 estudiantes nuevamente }\end{array}$ \\
\hline
\end{tabular}

\section{Recogida y tratamiento de los datos}

Se observa a un grupo de veintidós alumnos de segundo de bachillerato de diferentes opciones académicas. De los veintidós alumnos se recogen las calificaciones y comentarios de las pautas de los grupos de crítica (GC) de toda la clase y la justificación que del segundo borrador hacen los estudiantes. Asimismo, se realiza un vaciado y categorización de los elementos que los veintidós alumnos comentan en las pautas del GC. Se acompaña esta categorización de una gráfica de resultados. También se han recogido las pautas de autoevaluación de todos los grupos de trabajo (GT) de la clase, un total de ocho GT formados para trabajar este comentario lingüístico específicamente.

El análisis más específico lo acotamos con datos de tres grupos de alumnos, todos ellos con competencias diversas y niveles de formación diferentes: el grupo DNJ, el grupo ACP y el grupo JOP. Los denominamos de esta forma en función de las iniciales de los nombres de sus componentes.

De estos tres grupos se recogen los nueve portafolios relativos al comentario lingüístico. Estos portafolios están compuestos por el esquema del comentario lingüístico (individual y consensuado en grupos de trabajo [GT]), el primer borrador (B1) y el segundo borrador (B2). Los tres grupos han redactado un único comentario lingüístico que llamamos definitivo. Por lo tanto tenemos un comentario lingüístico definitivo y tres portafolios por grupo. Entendemos aquí como portafolios el conjunto de evidencias, ordenadas según la temporalización de su realización, que muestran la progresión del aprendizaje de una o un estudiante a lo largo de un período determinado de tiempo. La confección de portafolios en la enseñanza implica una mayor atención a la evaluación formativa del alumnado, a su evolución como aprendiz de una materia o de un aspecto de esa materia.

Además, se ha realizado una entrevista de carácter abierto con un miembro de cada grupo: con D (grupo DNJ), con A (grupo ACP) y con J (grupo JOP). Las tres 
entrevistas son grabadas; de ellas se realizan transcripciones informales para el estudio de determinados aspectos que interesan a la investigación.

Cada grupo de datos se ha trabajado de manera diferenciada ya que obedecen a objetivos también diferentes y el número de informantes de cada uno es variable. Finalmente se relacionarán estos tipos de datos diversos para que aporten una visión de conjunto. Ver cuadro 5.

Cuadro 5: Relación entre datos e informantes

\begin{tabular}{|ll|l|}
\hline \multicolumn{1}{|c|}{ Datos } & \multicolumn{1}{c|}{ Informantes } \\
\hline - & $\begin{array}{l}\text { Evaluación de la guía de } \\
\text { crítica } \\
\text { - Autoevaluación del GT }\end{array}$ & 22 (todo el grupo clase) \\
\hline - & $\begin{array}{l}\text { Borradores B1 y B2 } \\
\text { Texto definitivo }\end{array}$ & $\begin{array}{l}\text { 3 GT (9 alumnos y } \\
\text { alumnas) }\end{array}$ \\
\hline - & Entrevista & 3 alumnos \\
\hline
\end{tabular}

En los datos relativos al proceso de composición (evaluación de la guía de crítica, portafolios y texto definitivo), se establecen categorías relacionadas con las propiedades del texto: adecuación, coherencia y cohesión, más una categoría relativa a los contenidos explicitados acerca de la reflexión que se hace sobre la lengua, todas ellas con subcategorías asociadas. En los datos que tienen que ver con la metodología (autoevaluación del GT, entrevista), se retoman las preguntas de la investigación, de manera que en la síntesis resulte más sencillo relacionarlas todas y establecer interpretaciones.

\section{Interpretación de los resultados}

Las interpretaciones que se deducen de la investigación parten de las preguntas que se formulaban al comienzo de la misma e intentan contestarlas.

\section{La escritura sobre la lengua, instrumento de mejora de la propia escritura}

Podemos afirmar que escribir sobre la lengua ayuda a mejorar la propia escritura. Las respuestas a estas cuestiones se desprenden de tres de los tipos de datos recogidos: de las evaluaciones contenidas en las pautas de la guía de crítica, del contraste entre los borradores y el texto definitivo, y de las entrevistas.

Destacaríamos en primer lugar la importancia que da el alumnado a la estructuración del comentario lingüístico. Se trataba de uno de los aspectos más 
demandados cuando se planteó la estrategia de E/A porque el contenido a exponer era mucho y el peligro de no escribir textos coherentes, también. El comentario lingüístico ya está muy estructurado, pero el trabajo con pautas ayudó a no perder de vista esa estructura. También se pauta el resto de aspectos del comentario lingüístico; éste era el elemento que más angustiaba a los estudiantes cuando se planteó la estrategia por lo que tenía de desconocida para todos ellos. A partir esa delimitación estructural, cuidan diferentes aspectos que imprimen personalidad al tipo de género discursivo que tratamos aquí y que se demuestra en el contraste entre borradores y textos definitivos, así como en las valoraciones de la guía de crítica y autoevaluaciones:

1. Tienen cuidado de no perder de vista la completitud de sus partes: el comentario ha de ser completo en todos sus apartados, según el esquema que se les planteó (cuadro 2)

2. Ejemplifican con palabras o fragmentos del texto para ilustrar sus afirmaciones

3. Conectan las diferentes partes

4. Se adecuan al registro y al contexto de escritura, a su situación comunicativa

5. Atienden a la corrección ortográfica y formal del texto

El primer punto anotado, el de la completitud de los elementos que conforman el comentario lingüístico, está relacionado con los contenidos lingüísticos del propio texto: la estructura marca una serie de elementos que han de estar presentes; si falta alguno, ni la estructura ni el contenido son los exigibles en un texto de estas características. En el contraste entre borradores y texto definitivo, el grupo JOP amplía paulatinamente el campo de estudio, o el grupo DNJ “se olvida” en el comentario definitivo de algunos puntos que sí habían aparecido en los borradores previos. Los alumnos son conscientes de lo que debe incluir un comentario lingüístico, las pautas les marcan los planos generales, pero no concretan los niveles específicos; por ejemplo, les guía sobre la presencia del plano morfológico, pero no sobre cada uno de los niveles morfológico, sintáctico, léxico y semántico que tienen; o se les alude a la presencia de los elementos del acto comunicativo, pero no se detallan cuáles son $^{2}$.. Son ellos los que deben completarlos acudiendo a los textos de consulta. Y generalmente lo hacen con éxito y lo valoran en las diferentes evaluaciones y autoevaluaciones que realizan. 
En cuanto a la ejemplificación, hay que decir que era uno de los puntos en que se insistió más y que afecta también a la reflexión sobre la propia lengua, ya que una manera de demostrar lo que se sabe es aportando ejemplos que clarifiquen ese contenido. Se les pedía que si hablaban, por ejemplo, de la abundancia de presentes atemporales en el texto, ilustrasen con citas algunos casos para demostrarlo. Se trata de una exigencia del texto, una convención del género, que intentan tener en cuenta y que les aleja del aprendizaje memorístico para hacerles aterrizar en la concreción del texto.

Por otra parte, el tema de las conexiones entre párrafos o de las ideas contenidas en los mismos párrafos no ha tenido un tratamiento igual en todos los casos. Mientras que unos grupos han sido capaces de utilizar los elementos de conexión o los marcadores discursivos adecuados, otros han tenido dificultades para hacerlo de una forma más o menos afortunada. La relación con la reflexión sobre la lengua se hizo patente en este punto.

Interesante es también el proceso de adecuación del texto que redactan los estudiantes. El hecho de tratar los elementos de la comunicación de manera insistente en el curso puede haber hecho conscientes a los estudiantes de que un texto de determinadas características tiene que dirigirse a un receptor que capte el mensaje en un contexto adecuado, y se tiene que tener conciencia de quién está hablando y para qué. En este sentido, comprobamos que uno de los cambios que se hacen en las revisiones de los textos consiste en sustituir unas palabras o expresiones más coloquiales por otras más formales. Se lo representan -viene a decir D en la entrevista- de un texto formal y el lenguaje debe hacerse eco de esa formalidad. Se acercan en muchos casos al registro estándar-culto y utilizan los términos específicos sin problemas; asimilan, en consecuencia, la situación comunicativa. Uno de los alumnos al valorar a un compañero en la pauta del GC plantea:

Fig. 1: Cita extraída de la pauta GC

A nivel de estilo, hace falta cambiar el tono por otro más formal, construir mejor las oraciones, a veces incompletas o donde se han omitido artículos o incluso verbos. Un buen comentario que simplemente tendrá que ser redactado un poco.

También adecuan la persona gramatical que habla. Mientras que en los borradores individuales se hablaba en primera persona del singular, en el texto colectivo se cambia por la primera persona del plural. Para consensuar el texto definitivo, el alumnado lee en 
voz alta el que considerará como texto base sobre el cual hará las modificaciones oportunas. A raíz de esa lectura en voz alta se apercibe de la incoherencia del singular en esa situación colectiva y reacciona de la manera más coherente con la situación comunicativa (pasan del "creo que" al "creemos que").

El último paso de los GT siempre es la corrección ortográfica y formal del texto. En ese sentido, también siguen las pautas de revisión del grupo de crítica, que sugiere ese plano de revisión en último lugar. Una vez estructurado y completado el trabajo, es hora de comprobar cómo está escrito formalmente. La revisión a unos les hace corregir errores; a otros les lleva a hipercorregirlos, es decir a corregirlos de manera inadecuada, de forma que cometen el error ortográfico después de pasar por la revisión.

2. La incidencia de la interacción entre alumnos en el proceso de apropiación de los conocimientos lingüísticos y del proceso de escritura

En un principio, la investigación se había propuesto observar la incidencia de la interacción entre alumnos sólo en el proceso de la escritura que llevaban a cabo, aunque finalmente se comprobó que también actuaba en la apropiación que de la lengua realizaba cada componente analizado de los GT seleccionados.

El primer elemento destacable es que los GC, tal como se habían planteado en un principio, es decir como grupos correctores que colaboraban en concienciar a cada uno de los individuos acerca de sus propios errores o carencias, no había sido útil. Se comprobó que las anotaciones que se encontraban en las pautas de la guía de crítica prácticamente nunca eran escuchadas o recogidas en las segundas versiones del comentario lingüístico, en los segundos borradores. Al preguntar a A en la entrevista, ésta responde:

Fig. 2: Transcripción de una entrevista

Porque luego, porque sí también, porque a lo mejor el GC te dice que tienes algo mal y luego tú lo pasas un poco por alto y cuando lo ves en el GT eso que te faltaba a ti lo entiende el otro muy bien, claro entonces te das cuenta.

Es decir, que lo determinante para el aprendizaje a partir del comentario lingüístico de los alumnos ha sido el GT y no el GC. ¿Qué es lo que propiciaba ese aprendizaje? D y A nos dan respuesta en la entrevista. El método que han utilizado sus GT ha sido similar. En primer lugar, cada componente del grupo ha de aportar al GT un borrador individual bien elaborado, serio. Después se leen los tres borradores del GT y se escoge 
uno que sirva de referencia o de base estructural a todos. Se vuelve a leer en voz alta el texto base y cada componente del grupo va proponiendo lo que se podría añadir o modificar. Por último, uno de los componentes del grupo se responsabiliza de editar el texto definitivo. Dice D en la entrevista:

Fig. 3: Transcripción de una entrevista

Bien, en nuestro grupo lo que hicimos fue coger los textos, juntar los comentarios y, a ver, la introducción leímos la introducción primero la mía y después...las otras y miramos la que estaba mejor y cogimos por ejemplo la mía y una frase de....(N)... que... mi comentario es mejor, pero si añades esta frase, pues queda mejor.

Este método tiene un problema, y es que en el "recorta y pega" se han dejado por el camino, especialmente en el grupo DNJ, parte importante de los contenidos que ya contenía el borrador que les servía como base. Probablemente se deba a que se han "traspapelado" los datos en el conjunto de signos de las modificaciones posibles. Se podría evitar si editan en la clase misma el texto definitivo con un ordenador que les permita actuar en el momento de la interacción y no a posteriori, cuando la discusión ya está fría. Además, el texto definitivo tendría una voz colectiva, mientras que de esta forma se encarga un solo alumno de sintetizar lo que han dicho todos y de pasarlo a limpio. Los resultados mejorarían.

Por lo demás, también tiene aspectos muy positivos, como advierte A en el fragmento de la entrevista citado antes, y es que la interacción permite concienciarse de los aciertos y de los errores, y, por lo tanto, se detectan mejor aquellas observaciones realizadas por el GC que habían sido obviadas porque no acababan de entenderse. La posibilidad de hablar aclara los conceptos de los participantes en la interacción oral, tal como reconoce D en la entrevista:

Fig. 4: Transcripción de una entrevista

En mi grupo pues ves que: $\mathrm{N}$ pues tiene parecido un comentario parecido al mío y en cambio pues $\mathrm{J}$ pues le falta un poco, pues él mismo se da cuenta de que le falta tal parte y que no ha hecho, o sea no es que sea un mal comentario pero que... no ha hecho un comentario tan bueno como, como los otros, y entonces puede ver las partes que tiene que mejorar, y esto también me pasa a mí, que... que...que te comparas con los otros y ves las partes que te faltan y esto...lo... te hace para mejorar.

Es el enriquecimiento que propicia el contraste. J, un alumno con dificultades, se conciencia de lo que le falta y aprende en el intercambio con los compañeros del grupo. D utiliza el término comparar. De hecho, es lo que están haciendo con sus comentarios: compararlos para extraer de ellos lo que más les puede aprovechar al comentario 
común. Pero no se limitan a comparar, porque de la comparación surge un nuevo texto, enriquecido, gracias a las diversas perspectivas con que se miran los individuales. La dinámica de grupos les ayuda a detectar y corregir errores, pero también a crecer en el aprendizaje individual.

Relacionado con este punto, advertimos determinadas valoraciones presentes en las autoevaluaciones que realizan los alumnos al final del proceso: es importantísimo que cada estudiante aporte un buen trabajo individual, fruto del esfuerzo y de la reflexión previos. A también lo deja claro en la entrevista, y J se queja, justamente, de que en su grupo no se ha tomado este punto demasiado en serio. Perciben que no se puede construir nada sin una base sólida y que la interacción provechosa sólo se dará si todos los componentes de un GT ponen el mismo esfuerzo por su parte. Es importante, tanto en el comentario lingüístico en tanto estrategia concreta de E/A, como en el resto de las actividades docentes, que se procure un espacio de reflexión individual antes de acometer un comentario o un trabajo colectivo. La suma de perspectivas es muy rica, siempre y cuando estos puntos de vista estén construidos desde la reflexión previa. Los ladrillos individuales han de ser sólidos para levantar el edificio colectivo. El andamiaje -en la metáfora de Bruner- lo proporcionará el profesor o la profesora, que acompañará en todo momento esa construcción impidiendo que haya fallas estructurales.

Por otra parte, podríamos distinguir dos aspectos de diferente aprovechamiento: el de la cohesión del texto y el de su adecuación al contexto lingüístico.

El primero ha sido más irregular. Mientras que el grupo DNJ ha realizado una integración de los dos textos bastante ajustada y correcta, incluso con algún momento de brillantez sintáctica -la unión de dos oraciones independientes de dos alumnos diferentes a través del conector de relativo cuyo, muy infrecuente entre el alumnado-, el grupo ACP ha tenido algunos problemas a la hora de cohesionar los dos textos de referencia y sus componentes han optado por construir en oraciones independientes, sin conectarlas, las ideas expuestas en ellos.

En el aspecto de la adecuación, sin embargo, comprobamos que el grupo ACP ha adaptado perfectamente el emisor a la realidad (ya no es un emisor el que habla desde los borradores individuales, sino un emisor colectivo el que se responsabiliza del comentario lingüístico grupal) y cambiando la primera persona del singular por la 
primera del plural. Además, todos los grupos en mayor o menor medida han intentado acercarse a un registro formal del lenguaje, perceptible sobre todo, no en el paso del primer al segundo borrador, sino en el paso de los segundos borradores al texto definitivo, el colectivo el que nace de la interacción de los componentes del grupo.

En la entrevista, A decía:..."cuando lo ves en el GT eso que te faltaba a ti lo entiende el otro muy bien”. Implica la verbalización, la explicitación, el comentario de viva voz el que permite que "te des cuenta", que se tome conciencia de lo que ocurre en el texto. En última instancia es el paso por la interacción oral la que acaba de ayudar a los alumnos y a las alumnas a ser conscientes de sus carencias o de sus errores. También han colaborado en ello, de manera previa, la distancia que se adquiere a partir de la lectura en voz alta, el tiempo que ha pasado desde que se escribió la primera versión del comentario lingüístico, la ayuda de la pauta... todo ello contribuye a la distanciación que se necesita para que la revisión sea efectiva. El primer paso, el de los GC, es recomendable, pero se manifiesta como necesaria la interacción en grupos de trabajo, en grupos de contraste y de co-construcción del conocimiento, evidente en estas palabras de A y reflejo de los estudios de Bereiter y Sacardamalia (1994) y Esteve (2002).

3. La influencia de la guía con pautas en el proceso de apropiación de contenidos y escritura

A se quejaba de la utilización que se había hecho de las pautas:

Fig. 5: Transcripción de una entrevista

Las pautas, o sea las preguntas y eso está bien, pero lo que nosotros hacemos yo creo que lo hacemos muy superficial... quiero decir, pues a lo mejor aquí te falta esto, para hacer un poco más de...

Podemos extraer una serie de reflexiones sobre este punto. En primer lugar, las pautas sirven para marcar el camino, para estructurar el texto. De hecho, son rígidas porque pretenden marcar justamente eso, la estructura. No obstante, esas pautas deben complementarse con otros materiales teóricos de soporte, y lo dejan muy claro los estudiantes. Esos materiales son el comentario lingüístico teórico, sobre todo, y los de Estudio de la lengua y características específicas de los textos científicos. De hecho, la idea de la guía a partir de pautas surgió como la necesidad de indicar el camino de la escritura que habían demandado los mismos estudiantes ante la abundancia y complejidad del comentario lingüístico. 
En segundo lugar, al ordenar el proceso de escritura, se ordena también en una vía paralela el proceso de apropiación de los contenidos. En este sentido, las pautas sirven a este doble propósito.

Finalmente, las pautas tienen escasa incidencia en los GC, pero resultan útiles a los mismos autores de los textos en el momento de ponerse a redactar los borradores. Las utilizan como pautas de escritura, como manifiestan en las entrevistas.

\section{Repercusión de la evaluación mutua y la autoevaluación del alumnado en el proceso}

Los comentarios y las valoraciones de los compañeros (evaluación mutua) no han repercutido en el trabajo final, por cuanto se han redactado de forma superficial, no han profundizado en los errores y no se han propuesto alternativas, salvo en escasas excepciones. En la entrevista, A muestra su incomodidad al tener que poner una calificación a sus colegas, porque dice no estar preparada. La evaluación entre iguales no siempre es fácil, pero de manera especial cuando la pauta se ha contestado superficialmente.

Por encima de todo destacan los beneficios del trabajo colaborativo. Ya se ha explicado la metodología que siguen la mayoría de los GT para llevar a cabo su objetivo, la redacción de un comentario lingüístico consensuado entre los tres miembros del equipo. Hablan también de la estructura o de la ordenación de los contenidos y de las aportaciones de todos al trabajo común. En definitiva, de un modo de hacer al que no están demasiado habituados pero que, dicen, les ha ayudado a colaborar y a aprender. J corrobora en la entrevista: a fijar esos contenidos en la memoria:

Fig. 6: Transcripción de una entrevista

...si a mí me dan un esquema y me dicen ahí lo tienes, apréndetelo, pues la verdad no me entra.

En cambio, aplicándolo, entendiéndolo con ejemplos y cosas, pues de ahí no se mueve...

Creemos que a través de esta valoración final han podido explicitar todo aquello que ha funcionado. Interesante es que no hayan destacado ningún elemento negativo de la estrategia. Probablemente se deba a que se han quedado con los beneficios más que con los aspectos mejorables y no a que realmente no los haya. Por supuesto, no se descarta que sea una forma más de "agradar” a la profesora que los evalúa. Es uno de los inconvenientes de la investigación-acción, en que la misma investigadora es también la docente. 


\section{La apropiación de los contenidos de lengua}

Era inevitable que los contenidos de lengua surgieran en un trabajo como éste, en que está tan relacionado lo que se dice como la forma que adopta lo que se dice. De entrada, no era objeto de la investigación detenernos pormenorizadamente en este tema, pero se relaciona con el primer punto, con la pregunta general de la investigación y con su objetivo general, y era necesario tenerlo en cuenta. Los datos de los que surgen estas alusiones son tres: la parte de la evaluación que contenía la guía de crítica, el contraste entre borradores y texto definitivo y las entrevistas a los tres alumnos seleccionados.

Como todo ejercicio evaluable de cualquier asignatura, les preocupa que estén presentes todos los contenidos del mismo. En evaluación individual del ejercicio de cada compañero les hacen notar si está completo el comentario o falta añadir algún dato. Además, resaltan el hecho de que esos mismos compañeros hayan entendido correctamente lo que estaban analizando. Este aspecto es importante porque calibra lo que han podido procesar por sí mismos. Si la base conceptual de la lengua, la morfología sobre todo, se daba por sabida, como ocurrió, en el comentario lingüístico se trataba de aplicar esa base conceptual que aparecía desligada de cualquier contexto a un texto específico perteneciente a un género discursivo concreto. Era, pues, un contenido que debían rescatar de la memoria y procesar de forma autónoma, con lo cual se les impelía a autorregular ese conocimiento: aplicar e interpretar los conocimientos y datos del texto que debían comentar.

¿Qué queremos decir cuando hablamos de la interpretación de los datos del texto, es decir de los elementos que se encuentran en él? Es un punto en el que se insistía bastante en clase, que se ofrecía ya desde el texto modelo que se elaboraba entre todos y que en cierta forma monitoreaba el comentario lingüístico que ellos debían redactar. De hecho, el mismo comentario lingüístico teórico estaba enfocado desde esta perspectiva, basada en la lingüística del texto, y, dentro de ella, en la gramática del texto. Se les hacía entender que nada de lo que hay en un texto es gratuito, que todo está relacionado con el texto específico que se estaba trabajando, porque respondía a ciertas convenciones de su género, y con la situación comunicativa en que se producía, que lo condicionaba; y que, por ejemplo, cuando se comentara la presencia de abundantes sustantivos abstractos, deberían explicar por qué se producía esa presencia. Al final, 
todos los trabajos presentados contenían esa parte fundamental del análisis, con lo cual estamos en condiciones de afirmar que fue asimilada.

J, en la entrevista, marcó este aspecto como uno de los elementos esenciales de su aprendizaje en este curso. Asegura lo siguiente:

Fig. 7: Transcripción de una entrevista

¿Qué he aprendido de lengua? Pues muchas cosas, porque si a mí me dan un esquema y me dicen ahí lo tienes, apréndetelo, pues la verdad no me entra. En cambio, aplicándolo, entendiéndolo con ejemplos y cosas, pues de ahí no se mueve... y cosas concretas: usos del SE, las impersonales, bueno esas ya me las sabía, y después ejemplificación de las adverbiales...

En cuanto a la aplicabilidad de los conceptos que se imparten, nos fijamos en J. Este alumno es repetidor de segundo de bachillerato, por lo tanto los conocimientos de base ya los tenía. Lo que está destacando es que es ahora cuando les encuentra sentido porque se ven en un texto concreto. Y no sólo eso, sino que es esa aplicabilidad la que hace que se fijen en la memoria y, por lo tanto, que haya un aprendizaje real y duradero, no momentáneo para salvar el curso y después olvidarlo. En bastantes ocasiones los docentes se han preguntado de qué iba a servir al alumnado conocer una serie de reglas gramaticales y sintácticas desligadas de un contexto más o menos real que les diera sentido. J nos lo reprocha. En este modelo aplicado, él encuentra sentido a todo aquello que antes había aprendido sin saber qué finalidad podía tener. En los centros docentes se suele argumentar para justificar este modelo de E/A que no todo aprendizaje debe conllevar una utilidad, no todo debe servir para. Pero lo cierto es que hacerlo de este modo puede llevarnos a lo que consideramos desde aquí que son aspectos evitables:

a. A una excesiva teorización con pocos puntos de ajuste con la realidad. El saber conceptual es absolutamente necesario, pero no de cualquier modo, no se trata de saber por saber, sino de saber para poder utilizar ese conocimiento en la mejora de las propias competencias como usuario de una lengua. En el caso que nos ocupa, el comentario lingüístico pretende utilizar el conocimiento de la lengua como mediador en el proceso de escritura.

b. A una excesiva compartimentación de los contenidos que enseñamos en lengua. Por una parte, la gramática; por otra, el texto; además, la escritura, desligada de las anteriores; o la comprensión lectora, con textos diferentes de los que utilizamos para hablar de la lingüística textual, y así podríamos seguir. Si la 
lengua es un sistema integrado, no podemos atomizar en las clases su estudio. Ya vemos dónde lleva a J hacerlo de esa forma.

Otro punto que se desprende de las entrevistas es el manejo de las fuentes de consulta utilizadas por el alumnado para realizar su comentario lingüístico. Para realizar el comentario lingüístico completo debían manejar los tres tipos de fuentes y sintetizar los conceptos que iban necesitando en cada momento. Aquello que los orientaba en esas necesidades concretas eran las pautas, que les situaban en el marco estructural del comentario. Podríamos establecer un triángulo de consultas para la elaboración del ejercicio (cuadro 6):

Cuadro 6: Triángulo de cómo se conforma el conocimiento en el comentario lingüístico

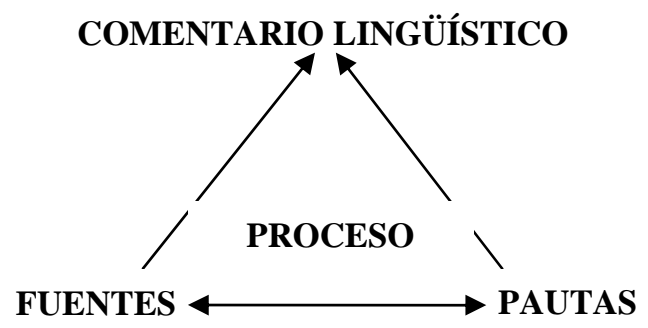

El objetivo al cual se debían dirigir era el comentario lingüístico, producto final que implicaba un proceso en el que intervenían dos factores: por una parte, la teoría, que a su vez estaba desglosada según el aspecto de contenido que debían desarrollar en su comentario lingüístico: desde los más gramaticales (Estudio de la lengua), pasando por los más específicos (características de los textos científicos) y los estructurales (comentario lingüístico teórico). Éstas son las fuentes. Ahora bien, ¿cómo orientarlos en su utilización para que la síntesis conceptual fuera efectiva? Esa misión la realizaban las pautas, cuya fuerte estructuración les hacía acudir en cada momento a la fuente precisa. Fuentes y pautas estaban, pues, en diálogo constante dentro del proceso de redacción del comentario lingüístico. J destaca dos de manera especial:

Fig. 8: Transcripción de una entrevista

Pues... tanto el que tiene por título comentario lingüístico de texto... eso es la Biblia, eso es la estructura básica... y... después los otros tipos de... cuando se comentan las características de los textos...

¿Por qué considera el comentario lingüístico teórico la Biblia? Allí estaba contenida la estructura global del comentario y todos los conceptos lingüísticos que necesitaban para elaborar un comentario lingüístico. J lo completaba con las características específicas de 
los textos científicos, que concretaba lo que debía buscar en el primer documento y otros materiales que hablaban de determinados elementos morfológicos que se les había facilitado a través del aula virtual:

Fig. 9: Transcripción de una entrevista

Eso que está hecho con esquemas, con colores y todo eso [Se refiere a las características específicas de los textos científicos]... Y después ya... para cosas concretas consulté en la web [el aula virtual] materiales ya más concretos que encontré y pueden ser... cosas de verbos consulté también...

Parece evidente, por lo tanto, que esta construcción compleja de la escritura se hace en interacción con los textos, diversos, que se ofrecen al alumnado, como un diálogo constructivo que permite levantar un andamiaje -en la metáfora de Bruner- en forma de red, en el cual se interrelacionan la construcción del conocimiento y el proceso de escritura para crecer juntos, ligados y profundamente dependientes.

Otro aspecto a tener en cuenta se encuentra en el contraste entre los borradores individuales del alumnado y el texto definitivo. Dice D en la entrevista:

Fig. 10: Transcripción de una entrevista

Alguien [al leer, para criticar, los textos de los compañeros] te habla de adjetivos calificativos y piensas, ostia, yo eso no lo he puesto... Y esto te lo apuntas y lo pones. O la sintaxis, dices... tres subordinadas... ya que lo pongo [en la pauta de crítica] lo voy a recordar porque en el mío no lo puse. Al corregir el comentario del otro vas viendo cosas que en el tuyo no has puesto y entonces pues.

El hecho de leer textos de otros compañeros y compañeras colabora a construir el edificio conceptual del comentario lingüístico propio. Ayuda a completar carencias, pero también a “ver cosas", en palabras de D, que no estaban en el propio pensamiento; por lo tanto, la lectura de los otros coadyuva a la progresiva conscienciación del proceso de escritura y del proceso de apropiación de contenidos gramaticales. Esas oleadas de maduración de contenidos se producen, por lo tanto, a partir de la progresiva conscienciación de los componentes lingüísticos que proviene en gran parte de la lectura de otros comentarios lingüísticos y, podemos aventurar, de la interacción con otros compañeros y compañeras del grupo de trabajo.

\section{La influencia de los textos de los compañeros para la elaboración de los propios}

Se trata de tema que ha surgido a lo largo de la investigación. Era extraño que, de forma recurrente, se obviaran los comentarios realizados por los GC, pero que sí hubiera cambios sustanciales del segundo borrador al comentario lingüístico definitivo 
no siempre procedentes de los segundos borradores de los componentes del GT, así que se pensó que la causa debía estar en otro lado.

Se acudió a una línea paralela de estudio sobre el tema "leer para escribir”. Se pensó en la posibilidad de que ocurriera que, leyendo textos de otros, pudiera avivarse la comprensión y la redacción de propio texto. En la pregunta ¿Te ayuda a mejorar tu expresión escrita el hecho de trabajar en GT, en GC, a partir de pautas, y por qué? respondieron que el leer textos de otros compañeros les había ayudado a completar contenidos que no tenían o a apercibirse de que se podían expresar mejor las ideas de otra forma. Hemos visto lo que D nos dice sobre ello en la entrevista; A, contestando a la misma pregunta, responde lo siguiente:

Fig. 11: Transcripción de una entrevista

A. Sí... porque a lo mejor una cosa que tenías explicada que te piensas que está más o menos bien, pues a lo mejor la ves de otra manera y te ayuda a modificar la tuya

I. ¿Eso lo dices en la teoría o en la práctica?

A. En la práctica

I. ¿Lo has llegado a hacer?

A. Sí. Por ejemplo, una vez me dejé lo del acto de comunicación... claro puse a lo mejor el emisor, el receptor y algo así, pero ni el mensaje... y todo eso, y entonces pues...

A no sólo se refiere a la parte de los contenidos en la primera parte del diálogo, Eso “ver de otra manera” alude también a otro enfoque o perspectiva del contenido, a otra forma de hacerlo explícito. Tampoco habla de "añadir”, sino de “modificar” su propio texto a partir de lo que ha leído en otros, con lo que estaríamos ante una posible interpretación en la línea de D de que leer textos de otros colabora en la mejora de la expresión escrita del propio texto. En el contraste entre el primer borrador y el segundo, realmente podemos comprobar que ha habido una modificación del contenido, en la línea que apunta A, bien añadiendo algo que se había dejado olvidado, bien modificando el punto de vista sobre algún aspecto del texto.

Sería interesante comprobar, en una nueva línea de investigación, de qué forma, en qué medida y en qué aspectos influyen los textos que los alumnos leen de otros compañeros en la forja de la composición escrita y de los contenidos expuestos del propio texto. 


\section{Conclusiones}

Escribir sobre la lengua aporta conocimientos sobre la manera de escribir sobre la lengua. El comentario lingüístico ha aportado elementos imprescindibles a la hora de plantearse la escritura de este género que podemos sintetizar a partir de las propiedades del texto:

- La adecuación del texto a la situación comunicativa, en la que imaginaban un receptor entendido, un registro formal, un léxico especializado y un emisor colectivo ya que se trata de un grupo de trabajo constituido por tres componentes

- La coherencia entre los diferentes aspectos que se tratan en el texto, de forma que han tenido especial cuidado en establecer una estructuración clara del propio escrito, a partir de marcadores estructurales en muchos casos, lo cual les ayudaba a identificar esos marcadores en textos de contextos similares y a realizar las transferencias oportunas, y en ejemplificar, tal como se les pedía, cada una de las afirmaciones que se hacían en el comentario lingüístico.

- La cohesión del propio escrito, fundamentada en la reformulación de estructuras oracionales, en la utilización de marcadores o conectores oracionales apropiados, en los mecanismos de cohesión léxica y en algunos cambios ortográficos que pretendían el acercamiento a la norma.

El papel de la interacción entre alumnos en el proceso de apropiación de los conocimientos lingüísticos y del proceso de escritura es uno de los elementos que han destacado más los estudiantes. En los centros de secundaria no hay una clara cultura de intercambio en las aulas, de interacción real entre estudiantes, y la relación con el docente se limita en muchas ocasiones a la típica de "profe habla, y estudiante escucha y responde a sus preguntas". El hecho de poder intercambiar texto y opiniones, de ser escuchados, les sorprendió y les costó adaptarse a la nueva situación de E/A. Una vez habituados, los momentos de interacción no solamente fueron un acicate para el aprendizaje y la construcción de conocimiento compartido, sino que además fueron un elemento de descubrimiento de la zona de desarrollo próximo de la que habla Vigotsky y de avistamiento y creación de estrategias de negociación por lo general fecundas para los estudiantes. El contraste de diferentes puntos de vista enriqueció las perspectivas 
desde las que miraban un mismo texto y les ayudó a construir un contenido lingüístico más completo.

No obstante, también tiene sus puntos negros. Por ejemplo, la constitución de los grupos que, aunque fue voluntaria y cada individuo se asoció con quien le apeteció, evidenció algo frecuente en grupos de trabajo: si hay un alumno o una alumna que descuella por encima de los demás, es también quien se lleva la mayor parte del trabajo, que deja de ser ya colectivo para ser dirigido por ese estudiante concreto.

La diversidad de métodos de interacción y de construcción de grupos (de trabajo, de crítica) llevada a cabo en esta estrategia de E/A, generó un elemento interesante. La lectura de los textos de otros compañeros y compañeras se había quedado agazapada en los entresijos de la memoria y del entendimiento del alumno o de la alumna, en forma de conocimiento implícito, esperando el momento en que podía verbalizarse y, por lo tanto, materializarse en palabras, en compañía de los colegas del grupo de trabajo, que tenían el objetivo de consensuar un único texto enriquecido por todos. Se trataba de una lectura que les hizo aprender; la interacción con los otros pudo verbalizar ese conocimiento.

La contribución, a esa apropiación, de la guía con pautas creemos que fue decisiva. Cumplieron dos objetivos: el primero, el de marcarles el camino de la escritura, el de ayudarles en la estructuración del texto -el elemento de la escritura que más les preocupaba en un principio y que originó la estrategia que se ha descrito y estudiado--. El segundo, el de ayudarles en la apropiación de los contenidos lingüísticos de los que hablaban en el comentario lingüístico, ya que les hacía repasar cada uno de esos contenidos y razonarlos.

Las pautas también tuvieron un aspecto negativo. Más que ser útiles para los receptores de la guía de crítica, fueron útiles para los mismos críticos-autores de los textos, que tuvieron que repasar estructura y contenidos presentes en las pautas para redactar sus propios textos.

La ayuda, en el proceso de apropiación, de la evaluación mutua y la autoevaluación del alumnado según unos criterios preestablecidos contribuyó a concienciarlo de los errores y de los aspectos mejorables del propio escrito. En la valoración del proceso que hace el alumnado, destacan los elementos positivos, como el 
trabajo colaborativo y la retención en la memoria de los contenidos importantes, pero no aluden a los negativos del proceso. Probablemente, y tal como manifiestan en la entrevista, porque los beneficios han sido más que las cosas mejorables, tanto a la hora de encarar la escritura como a la hora de interiorizar los conocimientos sobre la lengua.

Escribir sobre la lengua aporta conocimientos sobre la lengua. En este punto destacamos, en primer lugar, la transferibilidad de los conocimientos sobre los que han escrito. Escribir sobre la lengua en un género como el comentario lingüístico les hace aprender lengua y reconocer determinados rasgos lingüísticos en textos similares. Los estudiantes se han acostumbrado a interpretar, a razonar la aparición de determinados elementos característicos de un texto, a preguntarse por qué aparecen ésos y no otros a través de los borradores que iban construyendo, también de la interacción con los otros compañeros y compañeras de grupo.

Se han habituado a extraer de cada una de las fuentes de consulta los elementos que necesitaban en cada momento para poder "hablar de lengua". Se trataba de un diálogo entre el texto propio, las fuentes de consulta y las pautas-guía que les ha ayudado en su proceso de aprendizaje.

El hecho de reelaborar los textos repetidas veces les ha ayudado a tomar distancia respecto del propio texto. A ello también ha contribuido la visión los críticos han ofrecido a cada escritor, pero también los textos que ha criticado ese mismo escritor. Con esas críticas ha podido objetivar el conocimiento del a) texto comentado (científico en el caso de nuestra investigación) y b) de su propio comentario lingüístico, en contraste con las versiones de otros colegas.

\section{Referencias bibliográficas}

Bajtín, M.M. (1982) Estética de la creación verbal. México: Siglo XXI.

Bereiter, C, \& Scardamalia, M. (1994) Dos modelos explicativos de los procesos de composición escrita. Infancia y Aprendizaje, 58: 43-64.

Björk, L. \& Blomstrand, I. (2006) La escritura en la enseñanza secundaria. Los procesos del pensar y del escribir (4 edición). Biblioteca de Textos, 151. Barcelona: Graó.

Bronckart, J-P. \& Bain, D. (1985) Le fonctionnement des discours. Neuchâtel: Delachaux et Niestlé.

Bruner, J. (1986) Realidad mental y mundos posibles. Barcelona: Gedisa 
Camps, A. (coord.) (2003) Secuencias didácticas para aprender a escribir. Serie Didáctica de la Lengua y la Literatura, Barcelona: Graó.

Camps, A. (coord.) (2005) Bases per a l'ensenyament de la gramàtica. Biblioteca Articles, 146. Barcelona: Graó.

Camps, A. \& Zayas, F. (coords.) (2006) Secuencias didácticas para aprender gramática. Serie Didáctica de la Lengua y la Literatura, Barcelona: Graó.

Esteve, O. (2002): La interacción en el aula desde el punto de vista de la coconstrucción de conocimientos: un planteamiento didáctico, en M. Sagrario Salaberri Ramiro (coord.) La lengua, vehículo cultural multidisciplinar, pp. 6182. Madrid: Ministerio de Educación, Subdirección General de Información y Publicaciones

Jorba, J. \& Casellas, E. (1996) La regulació i l'autoregulació dels aprenentatges. Barcelona: Els llibres de l'ice de la UAB (Sèrie eines i Estratègies).

Milian, M. (2004). La enseñanza de la gramática: pensar la oración. Textos, 37: 36-51

Ribas, T. (1997) Evaluar en la clase de lengua: cómo el alumno gestiona su proceso de escritura. Textos de Didáctica de la Lengua y de la Literatura, 11: 53-65.

Vigotsky, L.S. (1995) Pensamiento y lenguaje. Buenos Aires: La Pléyade.

\footnotetext{
${ }^{1}$ Esta estructuración está tomada del manual Comentario lingüístico de textos, de María del Carmen Díaz del Pozo y Plácida Navarro Trujillo (PPU, 1987). La lingüística textual abordada por las autoras del manual posibilita un acercamiento a ese objetivo. Es un manual muy rígido en las formas y en los contenidos que expone. No obstante, se adapta a ciertas necesidades del nivel en que se imparte: en un segundo de bachillerato se necesitan referencias claras y sistematizadas a determinados contenidos lingüísticos. Estamos, pues, ante un guión si se quiere cuestionable, pero que sirve al doble propósito de escribir sobre lengua y de aprender lengua

${ }^{2}$ Ésta es la pauta de crítica, abreviada:
}

\section{Guía de crítica}

Pauta de evaluación para el grupo de crítica

Nombre del autor del texto

Nombre de quien realiza las observaciones

Contenido y aspectos estructurales

1. Observa las partes que contiene un comentario lingüístico. ¿Ha respetado el orden? ¿Lo ha redactado manteniendo los títulos de cada uno de los apartados o le ha dado un formato unitario?

2. ¿Deja claro qué tipo de texto es y su estructura? ¿Se podría mejorar? ¿Qué sugieres?

3. ¿Recoge claramente los elementos de la comunicación y las funciones lingüísticas presentes en este texto? ¿Qué falta? ¿Qué cambiarías?

4. En el nivel lingüístico, ¿ ¿has observado algún error o confusión en las afirmaciones que se hacen? Cítalas ¿ ¿alta algún plano o aspecto por comentar?

5. ¿Se han aportado ejemplos que ilustren los que se afirma? ¿Son pertinentes esos ejemplos? 
6. ¿ ¿Interpreta lo que aparece en el texto o sólo recoge datos? ¿La interpretación o las interpretaciones que se hacen son adecuadas / acertadas? ¿Por qué?

7. ¿Recoge en una conclusión-síntesis los aspectos esenciales del texto que se ha comentado? ¿Cómo sugieres acabar?

\section{Aspectos lingüísticos y de estilo}

1. ¿Qué palabras, expresiones, imágenes u otros detalles te parecen acertados y eficaces? ¿Por qué?

2. ¿Qué frases y expresiones te parecen innecesarias, ambiguas, repetitivas o mal formuladas? ¿Qué propondrías tú?

3. ¿Qué frases son demasiado largas, demasiado cortas o demasiado complejas y difíciles de seguir? ¿Qué propondrías tú?

4. ¿Están bien resueltos los vínculos o transiciones entre párrafos? ¿Cuáles cambiarías y por qué?

5. ¿Qué errores ortográficos o tipográficos has observado? ¿Cómo los corregirías?

\section{Calificación}

Calificación del contenido y los aspectos estructurales (sobre 7):

Calificación de la lengua y el estilo (sobre 5):

Justifica tu evaluación:

\section{Referencias de la autora:}

Inma López es catedrática de Lengua y Literatura Española en Educación Secundaria, Máster de Investigación en Didáctica de la Lengua y la Literatura de la UAB y formadora del ICE de la misma Universidad. Formada en la metodología de la práctica reflexiva, ha colaborado el Àrea de Programes de Formació del Departament d'Educació en diversos temas y protocolos relacionados con el asesoramiento en centros, el trabajo por competencias y la programación por competencias. Forma parte del grupo GREAL de la UAB. Tiene diversas publicaciones relacionadas con la lectura en Secundaria y el trabajo por competencias en el área lingǘstica, tales como: Llengua catalana i literatura, Llengua castellana $i$ literatura, Segon cicle d'ESO (Ed. ICE UAB ISBN: 84-89489-53-X, de autoría compartida), Llegir per aprendre. Una proposta per treballar les lectures a l'ESO (Sèrie Eines i Estratègies, 16. Els llibres de la UAB. ISBN: 84-89489-71-8 de autoría compartida) y La palabra compartida. La competencia comunicativa en el aula (Octaedro. ISBN: 978-84-9921-006-3, de autoría compartida). Mantiene diversos blogs de clase y un aula virtual de recursos y bibliografía en Espacio de Lengua: http://phobos.xtec.cat/ilopez15/.

\section{Email: ilopez62@gmail.com}

